\title{
Mediador y facilitador ;El mediador profesional del acuerdo, el facilitador profesional del perdón
}

\author{
mediator and facilitator: The professional mediator of the \\ agreement, the professional facilitator of forgiveness"
}

Francisco Gorjon-Gomez ${ }^{1}$

\section{Resumen}

El presente articulo evidencia la confusión que existe actualmente entre un mediador y un facilitador que ha provocado se le mal denomine al mediador en su desempeño profesional, ello debido al arribo del escenario de los Métodos de Solución de Conflictos (MSC) de la Justicia Restaurativa (JR) y al desafortunado criterio del legislador, que por considerar una habilidad dentro de una profesión sea esta la que determine su denominación, acreditación y certificación. La mediación en un procedimiento de solución de conflictos como en su caso lo es también la justicia restaurativa, pero con vocaciones diferenciadas, mientras que en la mediación su espectro es muy amplio (civil, familiar, comercial, etc.) en la justicia restaurativa se limita en este momento histórico a lo penal, aún que no descartamos que puede aplicarse en otras áreas del derecho. En la mediación se procura el acuerdo y solución del conflicto, en la justicia restaurativa se procura el perdón en su más amplia acepción de forma legal, moral y consustancial provocando una expiación y liberación de la culpa de víctima y victimario, no implicado su otorgamiento el incumplimiento o ejecución de sanciones establecidas en la ley derivado de las consecuencias del delito, mientras que en la mediación el perdón implica el no ejercicio de la acción penal y la reparación del daño como principales objetivos y está limitada solo a un catálogo especifico de delitos, si solo de mediación penal se tratara.

\section{Palabras Clave}

Mediador, Facilitador, profesión, habilidades.

\begin{abstract}
This article evidences the confusion that currently exists between a mediator and a facilitator that has caused the mediator to be misnamed in his professional performance,

\footnotetext{
${ }^{1}$ Doctor por la Universidad Complutense de Madrid, Miembro del Sistema Nacional de investigadores Nivel II, Profesor Investigador de Tiempo Completo de la Facultad de Derecho y Criminología de la UANL, México, Director Académico del Doctorado en Métodos Alternos de Solución de Conflictos de la Universidad Autónoma de Nuevo León, presidente de la Asociación Internacional de Doctores en Métodos Alternos de Solución de Conflictos ASID/MASC y del Colegio de Mediadores de Nuevo León. Email: fgorjon@hotmail.com. ORCID ID 0000-0001-5296-6454
} 
due to the arrival of the scenario of Conflict Resolution Methods (MSC) of Restorative Justice ( JR) and the unfortunate criterion of the legislator, that considering a skill within a profession is this one that determines its denomination, accreditation and certification. Mediation in a dispute resolution procedure, as in its case, is also restorative justice, but with differentiated vocations, while in mediation its spectrum is very broad (civil, family, commercial, etc.) in restorative justice. limits in this historical moment to the criminal, even though we do not rule out that it can be applied in other areas of law. In the mediation the agreement and solution of the conflict is sought, in restorative justice forgiveness is sought in its broadest sense in a legal, moral and consubstantial way provoking an expiation and liberation from the guilt of victim and victimizer, not implying its granting breach or execution of sanctions established in the law derived from the consequences of the crime, while in mediation, the pardon implies the non-exercise of criminal action and the repair of the damage as main objectives and is limited only to a specific catalog of crimes

\section{Keywords}

Mediator, facilitator, profession, skills.

\section{Introducción}

El presente artículo aborda el conflicto entre la distinción del mediador y del facilitador y de como la moda de la mediación penal y la Justicia Restaurativa termina subsumiendo a los otros tipos de mediación que son aun mas amplios y de mayor espectro que la materia penal. En el primer apartado determinamos como es que la mediación puede ya ser considerada una profesión y una ciencia social emergente, otorgándole otro rango al mediador como un profesional de la solución de los conflictos con amplia influencia social y reconocimiento internacional. En el segundo apartado hacemos la distinción doctrinal de mediador y facilitador justificando ampliamente sus diferencias y sus vocaciones y de como es necesaria su distinción, entendiendo que un mediador es un profesional de la solución de los conflictos y el facilitador es un auxiliar en el proceso de restauración, o de perdón de las víctimas y de los victimarios acotando el concepto a la materia penal, mientas que la mediación su ámbito de influencia u operatividad es ampliamente superior. En el mismo sentido en el tercer apartado evidenciamos esta confusión en la norma y de como de forma contradictoria regula a la mediación, a la conciliación, al arbitraje y a la justicia restaurativa, queriendo bajo una misma lupa observar los distintos procedimientos de MSC, quedando claro que esa contradicción es 
el mismo argumento para su separación y tratamiento diferenciado, ya que un mediador es un mediador, un arbitro es un arbitro y el profesional que atiende un procedimiento de

justicia restaurativa en alguna de sus etapas es un facilitador. Por último, en el apartado final de este articulo determinamos las diferencias procedimentales de la mediación y de la JR, así como establecemos su competencias o habilidades específicas, concluyendo que, aunque algunas inciden en otras, su profundidad e impacto es diferente, por lo que al fin de cuentas aun que suenan igual son disímiles, por lo que afirmamos que mediador y facilitador son entes diferentes.

\section{1.- La mediación como profesión}

Podemos afirmar que la mediación actualmente cuenta con todos los elementos necesarios para ser considerada una profesión y no solo una disciplina auxiliar del derecho como hasta ahora ha sido entendida. Actualmente la mediación esta reconocida ampliamente y cuenta con el más alto aval normativo ${ }^{2}$ y esta tutelada por diversas leyes y reglamentos administrativos; su reconocimiento no se limita solo a leyes nacionales, sino que va allende fronteras, reconocida y regulada en todo el mundo en leyes y reglamentos interno públicos y privados, leyes modelo internacionales, convenciones internacionales y tratados de diversa índole que reconocen su valía e importancia en el mundo de la solución de los conflictos, logrado una práctica homologada, multidisciplinaria, interdisciplinaria y multidimensional, abarcando la totalidad de la tipología del conflicto en un marco ecuménico de técnicas y habilidades, que no importa el lugar o el idioma, el mediador logra su objetivo, conforme a parámetros de voluntariedad que igualmente tienen un reconocimiento a nivel mundial, ya que la mediación a logrado lo que otras ciencias no, la armonización de las relaciones conflictivas en relaciones armoniosas con un impacto de bienestar subjetivo percibido que impacta en todas las relaciones humanas, trabajo, familia, amigos que una persona puede tener y tiene un impacto real en cuanto a la salud corporal o mental de las personas generando habientes factibles de convivencia, paz y felicidad.

\footnotetext{
${ }^{2}$ Articulo 17 de la Constitución de los Estados Unidos Mexicanos
} 
Igualmente se encuentra respaldada por un amplio background de saberes científicos, no podemos considerarla una profesión si no se le puede considerar una ciencia, y la mediación cuenta ya con ese rango científico, podemos afirmar que la mediación es una ciencia social emergente ${ }^{3}$. En razón de que se encuentra ubicada en la línea del pensamiento exponencial y no en el pensamiento lineal, su transición a ciencia esta bien definida por cinco dimensiones: La mediación como MSC, la mediación como procedimiento, la mediación como profesión, la mediación como ciencia y la mediación como objeto de estudios. Se sustenta un paradigma al igual que otras ciencias, en el paradigma de "resolver nosotros mismismos nuestros conflictos" como principal elemento transicional, se tiene identificados dos constructos con amplios elementos constitutivos validados científicamente con metodologías mixtas y no solo tradicionales, respaldada por más de 20 arquetipos que sustentan su cientificidad, teniendo como principio la impetración de la justicia y como fin la gestión y transformación del conflicto. De ahí que cuento nos referimos al mediador su contexto denominativo es muy fuerte, sus habilidades lo marcan contundentemente como profesional de la solución de conflictos. La mediación es una profesión en razón de los siguientes:

- Es producto de una necesidad social y tiene como fin último la sana convivencia en razón de interés propios y no solo la convivencia;

- Genera sus propias practicas que la distinguen de otras ciencias afines como es el caso del derecho, la psicología, la administración, el trabajo social, etc.

- Cuenta con sus propias técnicas y métodos para gestionar y transformar el conflicto;

- Genera un orden social que procura la sana convivencia de las personas y delimitada por su objeto que es la transición de relaciones conflictivas a relaciones armoniosas;

- Se sustenta en realidades, saberes auténticos y desarrolla habilidades y competencias especificas que permiten su desempeño profesional diferenciado;

\footnotetext{
${ }^{3}$ Mas de 10 investigadores y profesionales de los MSC conjuntaron esfuerzos para demostrar que la mediación es una ciencia social emergente, aportando argumentos contundentes y validos al respecto. GORJON, Francisco, Et.al, La ciencia de la mediación. Ed. Tirant Lo Blanch. México, 2015.
} 
- Se sustenta en el capital intelectual, y este a su vez en el capital humano, estructural y relacional, que determinan sus intangibles como valores positivos de amplio reconocimiento;

- Adaptabilidad sistémica (tipología conflictual) abarcando todo tipo de conflicto en el marco de la legalidad y el orden público, no ciñéndose solamente en aquellos previstos por la norma;

- Tiene un impacto bien definido "Armoniza las relaciones humanas y genera paz" complementario de su paradigma transicional.

Concluyendo que no puede ser que por una de sus habilidades "facilitar la comunicación entre las partes" entre otras muchas, se le encasille en esta última como un facilitador, es como considerar que un medico por tener dentro de sus habilidades y competencias el curar, se le denomine "curandero", o en su caso el arquitecto que por diseñar se le denomine "diseñador", o al Psicólogo que modifica el pensamiento humano procurando el bienestar de la persona se le llame "modificador de pensamientos" o el ingeniero que una de sus principales habilidades es la generación de modelos matemáticos se le denomine "modelero". Tenemos entonces que darle el mas amplio reconocimiento al mediador desde su perspectiva profesional de la solución de conflictos, como en su momento otras profesiones han surgido con sus habilidades y competencias específicas y con su propia impronta y la mediación tiene las suyas.

Aunado lo anterior la mediación como profesión no pude seguir considerándose alternativa si no, no podrá consolidarse como profesión, al ser una vía viable y contundente, que otorga resultados que evitan la vía judicial, en consecuencia, la vía alterna deberá ser la judicial y no la mediación o los MSC, que evitan tener que acudir a jueces o fiscales en un ambiente fuera de su control y de sus verdaderos intereses personales, entendido ello dentro de un marco de legalidad y respeto al orden público.

Los argumentos de la anterior afirmación son:

- Son un sistema integrado con características y principios propios por lo ue no se le pueden considerar alternativos;

- Se distingue de otros sistemas de solución de conflictos (sistemas retributivos, restaurativos, transicionales, terapéuticos, acusatorio, cotidiano, etc.) 
- Cuentan con un reconocimiento nacional e internacional en leyes y reglamentos internacionales;

- Apoya sustancialmente a otros sistemas de solución de conflictos de convivencia social determinados por políticas públicas o decisiones económicas

- Están homologados a nivel internacional

- Cuentan con un respaldo legal en razón de sus propias características, principios y modelos como son el circular narrativo, el transformativo o el tradicional o lineal por mencionar algunos;

- Son considerados una profesión (mediación) aun que actualmente no cuenta con su oficialización, pero si con los elementos para su operatividad;

- Son considerados una ciencia social emergente;

- Trabajan sobre paradigmas propios los cuales pueden ser definidos en el contexto de la gestión y transformación del conflicto.;

- Genera teorías propias a la par de generar nuevas como es el caso de la teoría de la impetración de la justicia, del valor intangible de los MSC, de la teoría funcionalista o de la teoría del bienestar subjetivo percibido;

- Establece una cosmovisión de la realidad en razón de interés personales y visto desde la norma, ya que el conflicto se aborda de forma diferenciada;

- Trabaja sobre un vacío investigativo identificado en las nuevas tendencias y modelos de convivencia y el pensamiento exponencial;

- Crea escenarios nuevos de vinculación social y resuelve problemas de amplio espectro teniendo como fin la sana convivencia, la paz y la felicidad;

- Desarrolla nueva forma de explicar y enseñar sus propios procesos de solución de conflictos.

\section{2.- Análisis del concepto de mediación y del facilitador visto desde la doctrina}

\subsection{Mediador}

Es muy importante establecer la diferencia entre un mediador y un facilitador. Ya ha quedado claro los elementos generales que determinan que la mediación es una profesión y una ciencia social emergente, hecho que en el contexto histórico se remonta al trabajo de mediadores y a sus resultados como profesionales en las últimas décadas, no señalamos bajo ninguna circunstancia que consideremos a la facilitación, como un profesión, si es 
que alguien quiere seguir esa tendencia, al contrario un facilitador si es un auxiliar del proceso de justicia restaurativa, a diferencia del mediador como señalaremos más adelante.

Existe un numero importante de definiciones de mediador, la doctrina especializada a trabajado bastante en este tema, al grado de lograr tipificar hasta tipos de mediadores, familiares, civiles, comerciales, comunitarios, penales, entre otros o considerar el tipo de mediador según el modelo utilizado (transformativo, narrativo, asociativo). Pero lo que nos interesa es conocer el concepto unificador de mediador que, no importando el tipo de conflicto mediado, en su mayoría el tipo de conflicto es quien lo define como un profesional en la solución de conflictos, sin embargo, señalaremos entonces más que la simple definición que conocemos a los elementos que la integran.

Los elementos que integran la definición de mediador son igualmente variados, sin embargo, indicaremos aquellos en donde existe la mayor incidencia de ellos en las diversas definiciones, me refiero a:

- Las partes en conflicto

- El conflicto

- El que conduce o administra el procedimiento

- El porque lo conduce o administra

- Las acciones que efectua para lograr que las partes soluciones su problema o problemas

- Las técnicas utilizadas

- La voluntariedad

- El fin que persiguen las partes

Citamos la siguiente definición como un eje ejemplificador de lo que creemos es el mediador, que en realidad es bastante simple, el mediador es: "aquella persona que media un conflicto entre dos o más personas y ayuda a resolver su conflicto". Así de simple es su definición, a partir de esta pueden agregársele los demás elementos antes señalados y construirla en las dimensiones que se necesite según el caso de la manera más simple o compleja que el autor quiera. Por lo que su delimitación para comprender que es un 
mediador dependerá más de sus habilidades y competencias que de sus elementos o características.

Siguiendo a Álvarez y Highton ${ }^{4}$ de la escuela argentina y autoras representativas del movimiento latinoamericano de la mediación y desde mi perspectiva las más calificadas para determinar que es un mediador, ellas señalan tres dimensiones para considerar que es un mediador: a) Los que actúan como promotores públicos y constructores del área; b) los que practican y ejercen la mediación como forma de vida de tiempo completo y c) aquellos quienes ofician de mediadores, pero sin considerarse ni ser profesionales de la mediación. Cito esta categorización, porque en los tres niveles varían las habilidades y competencias, sin embargo, coinciden en el interés de ayudar a resolver el conflicto en entre las partes. Y me remito nuevamente a la definición inicial "es aquella persona que media un conflicto entre dos o más personas y ayuda a resolver su conflicto".

El fin ultimo del mediador es mediar no facilitar, al respecto Barona Vilar ${ }^{5}$ señala "que mediar es la capacidad para ser neutral o equidistante funcional, respetuoso, objetivo, de confianza, paciente, perseverante, escuchante, asertivo, etc, que se requiere en el desarrollo de este procedimiento y que a la vez debe el mediador cumplir y ejercer su función mediadora".

Esto nos acerca al tema de las habilidades y competencias de un mediador es muy importante señalar cual es la función del mediador al respecto Álvarez y Highton señalan textualmente "los mediadores, así como otros profesionales, tiene preconceptos de su trabajo y de las funciones que desempeñan. Este preconcepto puede influir fuertemente en las reacciones de un mediador ante dilemas éticos, los mediadores se ven a sí mismos incluidos básicamente... en lo siguiente.... Componedores, enmendadores, protectores, capacitadores, reconciliadores" ${ }^{\prime 6}$ y porque no decirlo también como facilitadores. Pero entendamos que son, como nuestras autoras señalan funciones.

\subsection{Facilitador}

\footnotetext{
${ }^{4}$ HIGHTON, Elena I. ÁLVAREZ, Gladys S. Mediación para resolver conflictos. Ed. Ad - Hoc. Argentina, 1998.p. 213.

5 BARONA VILAR, Silvia. Mediación Penal. Fundamentos, Fines y régimen jurídico. Ed. Tirant Lo Blanch. Valencia, 2011. p. 355.

${ }^{6}$ HIGHTON, Elena I. ÁLVAREZ, Gladys S. Mediación para resolver conflictos. Ed. Ad - Hoc. Argentina, 1998.p. 372.
} 
Antes de determinar que es un facilitador es importante destacar que justicia restaurativa y mediación no es la mismo, son procedimientos diferenciados, al respecto Zehr ${ }^{7}$ quien es considerado el padre de la JR es muy enfático en este tema señalando que: "mediación no describe adecuadamente lo que podría suceder en los encuentros restauradores..." y amplia señalando que: "para participar en encuentros restauradores, los ofensores siempre tienen que aceptar en alguna medida la responsabilidad de su delito, puesto que un componente importante de tales programas consiste en identificar y reconocer el mal causado. El Lenguaje neutral usado en los procesos de mediación puede ser engañoso y a veces hasta resulta ofensivo para las víctimas"

Ahora bien, analicemos que o quien es un facilitador, siguiendo la misma lógica pretenderemos ser los mas simple posibles al respecto Junco $\operatorname{Vargas}^{8}$ señala que "el facilitador es un gestor de un proceso organizativo y es quien proporciona elementos para que los sujetos puedan concretar una misión”, en este caso un objetivo, lograr el perdón.

La JR se sitúa en la vía penal y a diferencia de la mediación la justicia restaurativa se centra en el daño, en las ofensas que conllevan obligaciones, promueve el compromiso la participación, en concreto "la justicia restaurativa requiere, como mínimo, que atendemos los daños y necesidades de las víctimas, que instemos a los ofensores a cumplir con sus obligaciones de reparar esos daños e incluyamos a las víctimas, ofensores y comunidades es este proceso" ".

$\mathrm{Al}$ respecto y de forma esclarecedora $\operatorname{Rey}^{10}$ señala que: "La Justicia restaurativa no solo se expresa mediante la mediación o la conciliación, ya que debe contarse con la anuencia de varias partes para que se propicie el encuentro. Muchos programas de justicia restaurativa se organizan alrededor del encuentro entre el ofensor, la victima y otros miembros de la comunidad o de la familia..." continua señalando que es fundamental trabajar en la dignidad de la victima y no solo en el acuerdo "...la dignidad humana vinculada a la integridad moral y psicológica de la víctima, juega un papel importante

\footnotetext{
${ }^{7}$ ZEHR, Howard. El pequeño libro de la justicia restaurativa. Ed. Good Books. España. 2007. p. 31.

8 JUNCO VARGAS, José Roberto. La conciliación. Aspectos sustanciales y procesales en el sistema acusatorio. Ed. Temis. Bogota, 2007. p. 23.

${ }^{9}$ ZEHR, Howard. Op.cit.

${ }^{10}$ REY NAVAS, Fabio Iván. La justicia restaurativa como un fin de la pena. ED. Ibáñez. Bogotá, 2018. p. 171.
} 
en los procesos restaurativos pues tras el delito la victima experimente la sensación de pedida del control sobre su vida y su seguridad, pero mediante la participación en estos procesos puede retomar el control de su existencia”.

Todo ello implica que “... la victima requiere comprender la dimensión de lo ocurrido, necesita información, por eso que desea una explicación somera, sino real: ¿Por qué sucedió?, ¿Por qué ella? Preguntas en las que, a veces, la única fuente de respuesta es el ofensor, ya sea directa o indirectamente".

Esta disquisición de Rey ${ }^{11}$ contextualiza para los efectos de este articulo la distinción entre los actores participantes en la mediación y la JR, ya que la restauración simboliza la reivindicación de la victima y no simplemente la reparación del daño visto desde la mediación, ya que la víctima necesita “... apreciar la preocupación o el esfuerzo por parte del ofensor de reparar el daño causado, de asumir la responsabilidad, de pedir perdón, $u$ otras formas que permitan aliviar la carga de dolor y culpa que puedan estar presentes en la victima ya sea esta individual o colectiva".

Al respecto Kemelmajer define al facilitador como "un tercero imparcial cuyo rol es facilitar la participación de la victima y del ofensor es un programa común. Cualquier programa de JR se vale de alguien llamado facilitador, reclutable en muchos sectores de la sociedad, no solo en los hombres y mujeres de derecho". Esto tiene dos significados primero sitúa a la JR solo en la vía penal y segundo le da el carácter de multidisciplinariedad ello implica que se requerida de una alta especialización en los temas concéntricos del conflicto penal como actualmente lo vemos incidiendo principalmente la psicología y el trabajo social, por lo que estos profesionales serán facilitadores de procedimiento de JR y porque no decirlo el mediador también podrá ser un facilitador dentro de un procedimiento restaurativo.

$\mathrm{Al}$ respecto Tamarit ${ }^{12}$ señala que un procedimiento de justicia restaurativa es mucho más complejo que una mediación, por lo que requerirá entonces de mas profesionales que ayuden a lograr el efecto restaurativo entre víctima y victimario, de ahí que sean denominados facilitadores. Ampliando este tema señala Mojica ${ }^{13}$ que para lograrse este

\footnotetext{
${ }^{11}$ REY NAVAS, Fabio Iván. Op.cit. p. 172.

12 TAMARIT SUMALLA, Josep. Et.al. La Justicia restaurativa desarrollo y aplicaciones. Ed. Comares. Granada, 2012. p. 15.

${ }^{13}$ MOJICA ARANQUE, Carlos Alberto Et.al. Justicia restaurativa. Hacia una nueva visión de la justicia penal. Ed. Universidad de Medellín. Medellín. 2005. p. 21.
} 
efecto se requiere de la utilización de diversos métodos o prácticas que buscan la interacción entre el ofensor, la víctima, la comunidad y el Estado en un marco de igualdad y respecto de los derechos humanos. De las cuales conocemos algunos ya que varía según el país ${ }^{14}$, el encuentro victima ofensor, los círculos, las conferencias y por qué no, incluir también la mediación como un procedimiento más, independientemente de las juntas restaurativas.

Es evidente que la mediación se encuentra limitada a determinados delitos en el caso de la mediación penal y a determinados conflictos siempre y cuando sean materia disponible, sin embargo, la JR no tiene un límite como tal, ya que su fin último es el perdón de las partes no implicado su logro evadir sus obligaciones legales, causa del delito cometido. No es óbice que por ser mediador no pueda intervenir en un procedimiento de JR, al contrario, el mediador cuenta con habilidades suficientes para asistir el procedimiento, pero con sus limitaciones, ya que necesariamente se requiere de la complementariedad de otras profesiones para lograr los objetivos de la JR, entiéndase esto como una manera diferente de ver la justicia ${ }^{15}$, ya que por lo regular es el mediador quien abre un procedimiento restaurativo.

Derivado de lo anterior obtenemos la siguiente conclusión, no podemos denominar de la misma manera a quienes conducen los procedimientos de mediación y el procedimiento de justicia restaurativa es por ello necesario diferenciarlos, y dejar para la justicia restaurativa al facilitador y en la mediación al mediador, no pueden ser el mismo, como bien señala Zehr de ambos procedimientos, estando claramente diferenciados. Por lo tanto, aún que parezca una entelequia el facilitador para la justicia restaurativa y el mediador para la mediación, sus propias acciones los delimitan.

\section{3.- Análisis del concepto de mediación y del facilitador desde la normativa mexicana.}

La distinción doctrinal y como hemos determinado hasta el momento funcional y profesionalmente entre mediador y facilitador es clara, sin embargo, la normativa tiende a confundirla, y es necesario aclararlo, ya que si se esta planteando que la mediación es un profesión esta deberá tener un reconocimiento como tal, las diversas leyes en materia

\footnotetext{
${ }^{14}$ BARDALES LAZCANO, Erika. Medios alternativos de solución de conflictos y justicia restaurativa. Ed. Flores Editor. México, 2001. p. 123.

15 WACHTEL, Ted. Et.al. Reuniones de justicia restaurativa. Real justice y manual de reuniones restaurativas. Ed. International Institute for Restorative Practices. Pennsylvania, USA. 2010.
} 
de mediación o de justicia alternativa, hoy 26 vigentes en el país, reconocen al mediador, sin embargo, cuanto se trata de la certificación de habilidades para poder ejercer como tal, prevalece el concepto de facilitador, hecho que surge en el último lustro, en algunas de las leyes, principalmente en la Ley Nacional de Mecanismos Alternativos de Solución de Controversias en Materia Penal (LNMASCMP), que define al mediador para el tema de las juntas restaurativas lo que consideramos acertado, pero, también expresamente reconoce al mediador, privilegiando al facilitador en cuanto a su certificación, confundiendo entonces su vocación, al grado que el mediador penal es denominado facilitador, sumando en su entramado que el facilitador hace mediaciones penales, influenciando a su vez otras leyes que recientemente se han modificado, como es el caso de la ley del Estado de Nuevo León, en el 2017, efecto que se puede dar en otras leyes o mas grave aún en iniciativas de homologación nacional, por una política normativista del sistema judicial, a pesar de que se trata solo de metería penal, reproduciendo prácticas de este derecho, desplazando el concepto del acuerdo de mediación por el de acuerdo reparatorio.

A continuación, presentamos el siguiente análisis ${ }^{16}$ de acuerdo con LNMASCMP, publicada en el Diario Oficial de la Federación el 29 de diciembre de 2014, el objetivo de dicha ley es el establecimiento de principios, bases, requisitos y condiciones de los mecanismos alternativos de solución de controversias en materia penal que conduzcan a las soluciones alternas previstas en la legislación procedimental penal aplicable, siendo esto la mediación, la conciliación y la junta restaurativa.

Uno de los principales actores en los mecanismos alternativos en materia penal es el facilitador, quien según la ley nacional es un "profesional certificado del órgano cuya función es facilitar la participación de los intervinientes en los mecanismos alternativos", entendiéndose por "órgano" a la institución especializada en mecanismos alternativos de solución de controversias en materia penal y por "mecanismos alternativos" a la mediación, conciliación y junta restaurativa antes referidos.

Ahora bien, el artículo 21 de la Ley Nacional de Mecanismos Alternativos define la mediación como "el mecanismo voluntario mediante el cual los intervinientes, en libre

\footnotetext{
${ }^{16}$ El presente apartado fue elaborado en colaboración con la Dra. Melissa Adame como parte de un ejercicio participativo de las diversas consultas para la aprobación de la Ley General de Mecanismos Alternativos de Solución de Controversias en materia Civil y Mercantil que hoy todavía se encuentra en discusión y en proceso de aprobación por el Congreso.
} 
ejercicio de su autonomía, buscan, construyen y proponen opciones de solución a la controversia, con el fin de alcanzar la solución de ésta" donde el facilitador fomenta la comunicación entre partes intervinientes, en tanto que el artículo 25 del citado ordenamiento jurídico refiere el significado de conciliación, que es "el mecanismo voluntario mediante el cual los Intervinientes, en libre ejercicio de su autonomía, proponen opciones de solución a la controversia en que se encuentran involucrados" y donde el facilitador puede proponer y presentar alternativas de posibles soluciones. Por otro lado, el artículo 27 de la ley en comento menciona que la junta restaurativa es "el mecanismo mediante el cual la víctima u ofendido, el imputado y, en su caso, la comunidad afectada, en libre ejercicio de su autonomía, buscan, construyen y proponen opciones de solución a la controversia, con el objeto de lograr un Acuerdo que atienda las necesidades y responsabilidades individuales y colectivas, así como la reintegración de la víctima u ofendido y del imputado a la comunidad y la recomposición del tejido social". Si bien la Ley Nacional de Mecanismos Alternativos de Solución de Controversias en Materia Penal conceptualiza al tercero neutral que coadyuva al desarrollo de mecanismos alternativos de solución de conflictos como un "facilitador", la citada ley y su conceptualización no excluye la denominación especial de dichos terceros neutrales dependiendo del mecanismo a implementar, es decir, que aunque la ley en mención señale que los terceros neutrales se les denominará como facilitadores en los mecanismos señalados en los artículos 21, 25 y 27, dichos facilitadores también pueden ser denominados conforme al procedimiento o mecanismo que están implementando, haciendo especial mención de la mediación y la conciliación ya que tiene vocaciones evidentemente diferentes, cuya denominación de tercero neutral que propicia dichos métodos son los mediadores y los conciliadores respectivamente.

Para sustentar lo anterior, nos permitimos referenciar nuevamente los conceptos de "mediador", “conciliador" y "facilitador" contenidos y ampliamente estudiados por la doctrina jurídica. En mediación, el mediador debe participar activamente, siendo que algunos elementos que conforman su rol son "facilitar el paso de la discusión dialéctica al pensamiento creativo-alternativo, aliviar la carga emocional, estimular la salida de 
posiciones rígidas, mostrar lo manifiesto del conflicto y ver más allá e invitar al cambio de roles" 17 .

Por su parte, la justicia restaurativa se lleva a cabo a través de juntas restaurativas, que conforme al artículo 28 de la Ley Nacional de Mecanismos Alternativos de Solución de Controversias en Materia Penal, dichas juntas son realizadas y guiadas por facilitadores para lograr acuerdos que las partes involucradas estén dispuestas a aceptar y cumplimentar, lo cual se puede confirmar de lo expuesto en la doctrina que señala que "la trascendencia jurídica de un acuerdo reparatorio es de orden público, amén de que se trate de un acuerdo entre particulares, ya que conlleva la participación de facilitadores oficiales y que se suscribe con la participación del Ministerio Público o el Juzgador”18.

De acuerdo con lo descrito, se hace una diferenciación entre los conceptos de mediador y facilitador, en razón de que el primero se utiliza específicamente para denominar al tercero neutral de la mediación, en tanto que el segundo se utiliza para nombrar al tercero neutral que interviene en los procedimientos de justicia restaurativa en materia penal. En las legislaciones de diversos países se considera también como "mediador" al tercero neutral que interviene en las mediaciones para guiar a las partes intervinientes en la comunicación para la solución de su conflicto, tal es el caso de Argentina, que en la Ley 26.589 de Mediación y Conciliación, en sus artículos 10, 11 y 16 se aborda el concepto del tercero neutral de la mediación como "mediador" y la propia ley lo reitera a lo largo de la misma.

En España, la Ley 5/2012, de 6 de julio, de mediación en asuntos civiles y mercantiles en el apartado III de la justificación y fundamentación de la ley, se establece que el mediador es "la pieza esencial del modelo, puesto que es quien ayuda a encontrar una solución dialogada y voluntariamente querida por las partes" a través de una intervención activa. De la misma manera, el artículo 1 de la Ley 5/2012 menciona lo que se entiende por mediación siendo ésta el "medio de solución de controversias, cualquiera que sea su denominación, en que dos o más partes intentan voluntariamente alcanzar por sí mismas un acuerdo con la intervención de un mediador", además de que los artículos 11, 13 y 14

\footnotetext{
${ }^{17}$ SÁNCHEZ GARCÍA, Arnulfo. Mediación y arbitraje. Eficacia y proyección internacional. México, D.F,: Tirant Lo Blanch. 2015. p. 16.

${ }^{18}$ GORJÓN GÓMEZ, Gabriel. (2016). "El acuerdo del proceso de justicia restaurativa". En A. SÁNCHEZ GARCÍA, Arnulfo \& LÓPEZ PELÁEZ, Patricia. (Edits.), Tipología contractual de los mecanismos alternativos de solución de conflictos (págs. 365-392). Navarra: Aranzadi, SA.
} 
establecen específicamente los requisitos y la forma de actuar que deberán tener los mediadores en materia civil y mercantil. Cabe mencionar que el "Real Decreto 980/2013, de 13 de diciembre, por el que se desarrollan determinados aspectos de la Ley 5/2012, de 6 de julio, de mediación en asuntos civiles y mercantiles" establece los lineamientos a seguir para la debida formación, registro e inscripción de mediadores que deseen ejercer como tal en España.

En México, específicamente en el estado de Nuevo León asume la postura de la ley nacional de forma errónea, ya que a vocación de esta ley es civil y no penal, la Ley de Mecanismos Alternos para la Solución de Controversias del Estado de Nuevo León, señala en su artículo 2 fracción XIV que el concepto de "facilitador" es toda aquella persona física que cuenta con certificación o certificación especializada del Instituto para prestar sus servicios de Mecanismos Alternativos, y que podrá ejercerlos, ya sea como árbitro, conciliador o mediador en el Instituto, en los Centros de Mecanismos Alternativos acreditados en los términos de esta Ley o en forma independiente". Así también el citado artículo 2 en su fracción XIX establece que la mediación es aquel "mecanismo alternativo voluntario mediante el cual los intervinientes, en libre ejercicio de su autonomía, buscan, construyen, y proponen opciones de solución a la controversia, con el fin de alcanzar una solución total o parcial. El facilitador durante la mediación propicia la comunicación y el entendimiento mutuo entre los intervinientes". Con dichas definiciones se puede resumir que un facilitador es una generalización del tercero neutral puesto que el propio artículo 2 refiere que un facilitador es cualquier árbitro, conciliador o mediador que cuente con certificación para desempeñarse como tal, siendo que el mediador es el facilitador específico para dirigir un mecanismo de mediación.

Asimismo, según el artículo 2 fracción X del Reglamento de la Ley de Mecanismos Alternativos para la solución de controversias para el Estado de Nuevo León, publicado el 24 de abril de 2017 en el Periódico Oficial del Estado de Nuevo León, un mediador es una "persona neutral e imparcial que interviene en la mediación para facilitar la comunicación entre las partes en una controversia, con la finalidad de que estas puedan generar opciones de solución al mismo y, en su caso, adoptar la más satisfactoria para ellas", definición normativa que afirma y reitera que el facilitador del mecanismo de mediación debe ser denominado como "mediador". 
Una explicación objetiva y directa a lo anteriormente es que el término de "facilitador" es una acepción general que incluye a diversos especialistas en diferentes mecanismos alternativos de solución de controversias, sin embargo, cada mecanismo alternativo cuenta con un tercero neutral específico cuyas atribuciones, facultades y alcances en los propios procedimientos son diferentes y, por consecuencia, no se les puede denominar de la misma manera ya que una misma denominación puede provocar confusión no sólo en los particulares gobernados sino también en los facilitadores como denominación general, así como en los mediadores y conciliadores como denominación especial, incluyendo también a los abogados y juristas que intervengan en los procedimientos, así como a los propios legisladores que elaboren ordenamientos jurídicos en mecanismos alternativos de solución de controversias en diversas materias a nivel federal y estatal.

Concluyendo el profesional que asiste la mediación deberá ser llamado mediador, el profesional que asiste la conciliación deberá ser llamado conciliador, el profesional que asiste el arbitraje deberá ser llamado árbitro, el profesional que asiste las juntas restaurativas debe de ser llamado facilitador.

\section{4.- Habilidades del mediador y del facilitador.}

\subsection{Alcances diferenciados de las habilidades del mediador y del facilitador}

Las habilidades y competencias del mediador y del facilitador son muy similares, algunas de ellas se comparten pero instrumentalmente son distintas, por lo que aun que se declaren como las misma, requirien de un trato diferenciado y de un alto grado de capacitación en la justicia restaurativa, como por ejemplo la empatía, el procedimiento per se hace que la misma competencias sea diferentes, no es lo mismo la empatía para lograr un acuerdo entre dos partes a la empatía para lograr el perdón, su uso y mantenimiento tiene el reto del tiempo y mayores elementos a considerar, más aún cuando esta competencia se comparte, entendiendo al proceso restaurativo como una labor de equipo y la mediación no necesariamente, el trabajo en equipo es mas una excepción que una regla.

Otra distinción es que mientras el mediador pretende que las partes logren un acuerdo en razón de sus intereses, y que el conflicto bien pueda ser un conflicto basado solo en posiciones, el facilitador busca que las partes se perdonen en conflictos (delitos) que van más allá de una posición, el daño ocasionado trastoca a la persona en niveles intrapersonales, en este caso el perdón no solo significa satisfacer una necesidad, el 
proceso es muy complejo que transita por diferentes estadios; el primero es el de la molestia e ira que implica lograr que las partes se despeguen de la culpa, se reconcilien y logren olvidar selectivamente; el segundo estadio es el de la serenidad y recuperación que implica control de la memoria natural, la reconciliación con la realidad y la voluntariedad de perdonar y por último el tercer estadio es el de la aceptación y liberación que implica la expiación del conflicto, la sublimación del conflicto y por último el Júbilo ${ }^{19}$. Para lograr todo ello la fluctuación de la empatía en ambos procedimientos es evidentemente y abrumadoramente diferente, además de poner otras en marcha como lo es la escucha activa, el reencuadre, etc.

En cambio el convenio de mediación implica lograr un acuerdo que en la mayoría de las ocasiones requiere del cumplimiento de una obligación, aun que a veces el acuerdo aborda cuestiones mas subjetivas que necesariamente tendrán que ser cumplimentadas para lograrlo, como el caso de una simple disculpa, sin embargo, no es una cuestión determinante en muchos casos, depende del conflicto, ya que la mediación también aborda conflictos con un alto nivel de complejidad, ello independientemente del modelo de mediación a aplicarse ya que no es lo mismo el modelo lineal de Harvard para casos de mediación comercial que el modelo circular narrativo en la mediación familiar, hecho evidentemente complejo de diferenciar, ya que los modelos establecidos en nuestras normas son modelos mixtos y se deja más a la intuición del mediador que al procedimiento mismo, evidenciando otra competencia del mediador que tendrá que ser intuitivo y lograr apoyar a las partes generando estrategias que su expertis o su experiencia le permitan.

Otra diferencia, mientras que el mediador puede lograr que las partes lleguen a un acuerdo de una manera rápida en una sesión, el facilitador requiere de mayor tiempo, la preparación de un procedimiento restaurativo puede llevar meses y el numero de sesiones en incierto, por lo que la paciencia se pone a prueba y se comparte con los miembros del equipo restaurador "si lo podemos llamar asís".

De igual manera podemos distinguir ambos procedimientos en razón de su presencialidad, en la mediación para lograr el acuerdo las personas en conflicto están presentes durante el procedimiento, en cambio en la JR no necesariamente, al grado que ante un homicidio

\footnotetext{
${ }^{19}$ RAMOS MORALES, María Leonor. Los elementos del perdón en la mediación familiar. Tesis Doctoral. Consultar repositorio del DMASC. www. Facdyc.uanl.mx. México, 2017.
} 
imprudencial el principal afectado esta muerto, y el que cometió el delito es perdonado por los padres, otro hecho a considerar es la inclusión necesaria de terceros, porque ante un echo de la magnitud mencionada, se ven afectadas familias y comunidades enteras, que de igual manera participan en el proceso de perdón y en su caso de reinserción.

Otro elemento a considerar es la especialización del mediador, no necesariamente tendrá que ser un experto en el motivo del conflicto, en muchas ocasiones basta con su experiencia de mediador para lograr que las partes lleguen a un acuerdo, esto es muy común en la mediación en sede judicial, en la mediación penal en las fiscalías, en la mediación municipal y también sucede en las centros privados, cuando los mediadores están ávidos de apoyar a la sociedad, a diferencia de la JR que el facilitador tendrá que ser verdaderamente un experto (psicólogo, trabajador social, abogado, etc), pensemos en una violación, en un homicidio o en cualquier otra delito que haya ocasionada un daño moral aparentemente irreversible, las variables a tratar son evidentemente especialísimas, mas complejo resulta cuando en el conflicto esta involucrado menores, el nivel de responsabilidad de potencializa y una mediación en este ultima caso se ve rebasada.

Y por último en cuanto a los objetivos de este apartado es relevante para comprender la distinción que se debe tener entre lo que podrían parecer las mismas habilidades, pero que no lo son, es la simplicidad del procedimiento, esta es tal vez la característica de la mediación mas exitosa, el ejemplo para comprenderla es el DAM, que en un rango de 5 a 12 minutos una persona conoce el procedimiento y sabe a que atenerse y que esperar de la mediación, en cambio en la JR el procedimiento puede durar meses por su nivel de complejidad, y esa variable transforma las habilidades y competencias del facilitador.

\section{2.- Habilidades del mediador}

A continuación, describiré de forma general las habilidades del mediador de forma genérica $^{20}$ sin enfocarnos a algún tipo de mediación, esto nos permitirá normar nuestro criterio al respecto d forma general, ya que estas competencias inciden en todo procedimiento, no necesariamente teniendo que aplicar todas siempre, ya que ello dependerá del conflicto y de los mediados.

- Conocen e identifican las materias que son susceptibles de mediar y conciliar;

${ }^{20}$ GORJÓN GÓMEZ, Francisco Javier y STEELE GARZA, José Gpe. Métodos Alternativos de Solución de Conflictos. 2da, Ed. México, 2015. p. 23. 
- Conocen los diferentes modelos de negociación y sus técnicas;

- Distinguen entre los diferentes modelos de mediación y/o conciliación;

- Conocen las técnicas de la mediación y de la conciliación;

- Son capaces de reestructurar la comunicación de las partes a través de técnicas de Comunicación;

- Desarrollan el sentido de la escucha activa;

- Desarrollan la técnica del parafraseo, el encuadre y el reencuadre;

- Conocen y aplican la técnica del Caucus como elemento sine qua non de la mediación conciliación;

- Conocen y aplican la técnica de control de la ira durante el procedimiento de mediación-conciliación;

- Conocen y aplican la técnica del rapport;

- Estructuran el plan de mediación y conciliación;

- Conocen las distintas etapas procedimentales desde el planteamiento del conflicto hasta el acuerdo;

- Son capaces de comprender la historia del conflicto para detectar si es susceptible de iniciar la mediación o la conciliación;

- Detectan las posiciones de las partes en conflicto;

- Detectan los intereses de las partes;

- Definen y distinguen las técnicas, teorías y conceptos asociados de control de crisis en un conflicto;

- Son capaces de motivar opciones para la solución del conflicto por parte de los involucrados;

- Concretan las opciones que favorezcan a las partes, que sean susceptibles de convenir y que no alteren el orden público;

- Son capaces de sustraer los intereses y necesidades mutuas de los protagonistas del conflicto;

- Elaboran el acuerdo o convenio en conjunto con las partes.

\section{3.- Habilidades del facilitador}


Zerh $^{21}$ nos marca directrices de la justicia restaurativa, que bien pueden ser consideradas para orientar la identificación de las habilidades y competencias que un facilitador debe observar indiscutiblemente.

Por lo que el facilitador se:

- Centrarse en los daños ocasionados por el delito, más que en las reglas violadas;

- Demuestra el mismo interés y compromiso hacia víctimas y ofensores, involucrando a ambas partes en el proceso de justicia;

- Trabaja por la restauración de las víctimas, ayudándoles a recuperar su sentido de control y atendiendo las necesidades que ellas mismas vayan percibiendo;

- Apoya a los ofensores, junto con motivarles para que entiendan, acepten y cumplan con sus obligaciones;

- Reconoce que, aun cuando las obligaciones de los ofensores puedan ser difíciles de cumplir, éstas no deben ser concebidas como castigo y deben ser realizables;

- Genera oportunidades para el diálogo directo o indirecto entre víctimas y ofensores cuando sea apropiado;

- Encuentra medios efectivos para comprometer a la comunidad y abordar las condiciones que dan origen al crimen dentro de la comunidad;

- Estimula la colaboración y la reintegración, tanto de víctimas como de ofensores, en lugar de la coerción y el aislamiento;

- Presta atención a las consecuencias imprevistas de nuestras acciones y programas;

- Demuestra respeto hacia todas las partes: víctimas, ofensores, colegas del sistema de justicia.

Al respecto observamos algunas habilidades inspiradas en Zerh para poder marcar una diferencia con las del mediador, auxiliándonos de algunos manuales y otros autores de referencia en el tema ${ }^{22}$.

De acuerdo a las Naciones unidas ${ }^{23}$ el facilitador debe tener:

\footnotetext{
${ }^{21}$ ZEHR, Howard. Op.cit. p. 49.

${ }^{22}$ Colaboración de los alumnos del Doctorado en Derechos Humanos y Solución de Conflictos de la UJAT. Dalila Vera Hernández; Julio César Valdez Silva; Juana Sánchez Ramos; Martha Guadalupe Calderón Castillo y Estefany Vidal Cano.

${ }^{23}$ DANDURAND, Ycon and GRIFFITHS, Curt T Manual sobre programas de justicia restaurativa. Viena: ONU. $2006 . \quad$ https://www.unodc.org/documents/justice-and-prisonreform/Manual_sobre_programas_de_justicia_restaurativa.pdf
} 
- Habilidad para crear un ambiente en que las partes sean libres y tengan interacciones seguras.

- Habilidades de comunicación (incluyendo habilidades especiales de lenguaje)

- Habilidad de manejar y ayudar a la gente a lidiar con la intensidad emocional.

- Habilidad de ayudar a las partes a decir y escuchar cosas difíciles.

- Habilidad de balancear los intereses/poder de los participantes.

Por su parte Choya $^{24}$ establece las siguientes:

- Equilibrar el poder entre las personas participantes.

- Conseguir que las partes en conflicto sean capaces de comunicarse adecuadamente en el proceso y aprendan a hacerlo también en el futuro.

Otra clasificación según Pranis ${ }^{25}$ establece que el facilitador:

- No juzgar ni personas ni ideas

- Saber manejar conflictos

- Conocer sobre manejo de grupos

- Sabe mantener tiempos

- Balancea procesos con contenido

- Conoce el tema a tratar

- Se conoce a sí mismo(a)

- Debe saber aceptar y reconocer que no todo saldrá perfecto

- Es capaz de mantener el Círculo como un espacio seguro para todas las personas

- Es respetuosa/o

- Buen comunicador

- Honesto

- Organizado

- Flexible

- Tener capacidad de síntesis

- Saber preguntar

- Tener vocación de servicio

24 CHOYA FORÉS, Nastia. Prácticas restaurativas: circulos y conferencias. 2015. http://www.pensamientopenal.com.ar/system/files/2015/07/doctrina41593.pdf

${ }^{25}$ PRANIS, K. Manual para facilitadores de círculos de diálogo en instituciones educativas. Fundación pedagógica nuestramérica. Costa Rica, 2009. 
- Ser amigable y honesto

- Ser abierto

- Saber escuchar activamente.

\section{Conclusiones}

- La doctrina distingue claramente la diferencia entre mediador y facilitador y los define divergentemente;

- Las vocaciones de un mediador y de un facilitador son diferentes;

- El fin ultimo de la mediación no es el mismo que el de la justicia restaurativa por lo que el mediador tiene una misión y el facilitador otra;

- La norma confunde al mediador y el facilitador y presupone para ambos las mismas habilidades;

- El facilitador opera específicamente en conflictos de tipo penal, mientras que el mediador su ámbito es en todas las áreas del derecho;

- Confunden al mediador penal en conflictos penales mediables con el facilitador;

- Si el conflicto no es mediable, él mediador no puede intervenir, pero si pude el facilitador como procedimiento restaurativo;

- Los requerimientos establecidos para certificación de facilitadores no son acordes al proceso restaurativo;

- Los requerimientos señalados por la CONATRIB, por la SETEC y por la CNPJ esta enfocados a las habilidades de un mediador mas que de un facilitador;

- Es necesario adecuar estos criterios a la Justicia Restaurativa y considerar la vocación del facilitador;

- Las técnicas de Justicia Restaurativa son más amplias que las utilizadas en la mediación no solo limitándose a las juntas restaurativas;

- La incidencia de técnicas en ambos procedimientos es lo que ha causado su confusión, sin embargo, la profundidad y la exhaustividad en su ejecución es lo que las diferencia;

- En la mediación la reparación del daño implica perdón legal mas no un perdón moral necesariamente, ya que se pueden llegar a acuerdos sin perdonar y solo reparar materialmente; 
- En la justicia restaurativa la reparación del daño implica perdón consustancial que involucra a la dignidad, la reivindicación, la integridad moral, la pérdida de control de vida y su recuperación, alivia la carga del dolor y la seguridad, algo que la mediación no puede proporcionar;

- La mediación es un puente para la Justicia Restaurativa;

- Por lo tanto, el mediador es un profesional del acuerdo y el facilitador un profesional del perdón.

\section{Referencias}

BARDALES LAZCANO, Erika. Medios alternativos de solución de conflictos y justicia restaurativa. Ed. Flores Editor. México, 2001.

BARONA VILAR, Silvia. Mediación Penal. Fundamentos, Fines y régimen jurídico. Ed. Tirant Lo Blanch. Valencia, 2011.

CHOYA FORÉS, Nastia. Prácticas restaurativas: circulos y conferencias. 2015. http://www.pensamientopenal.com.ar/system/files/2015/07/doctrina41593.pdf

DANDURAND, Ycon and GRIFFITHS, Curt T Manual sobre programas de justicia restaurativa. Viena: ONU. 2006. https://www.unodc.org/documents/justice-and-prisonreform/Manual_sobre_programas_de_justicia_restaurativa.pdf

GARCÍA, Arnulfo \& LÓPEZ PELÁEZ, Patricia. (Edits.), Tipología contractual de los mecanismos alternativos de solución de conflictos Navarra: Aranzadi, SA.

GORJON, Francisco, Et.al, La ciencia de la mediación. Ed. Tirant Lo Blanch. México, 2015 .

GORJÓN GÓMEZ, Francisco Javier y STEELE GARZA, José Gpe. Métodos Alternativos de Solución de Conflictos. 2da, Ed. México, 2015.

GORJÓN GÓMEZ, Gabriel. (2016). "El acuerdo del proceso de justicia restaurativa”. En A. SÁNCHEZ

HIGHTON, Elena I. ÁLVAREZ, Gladys S. Mediación para resolver conflictos. Ed. Ad - Hoc. Argentina, 1998.

HIGHTON, Elena I. ÁLVAREZ, Gladys S. Mediación para resolver conflictos. Ed. Ad - Hoc. Argentina, 1998.

JUNCO VARGAS, José Roberto. La conciliación. Aspectos sustanciales y procesales en el sistema acusatorio. Ed. Temis. Bogota, 2007. 
MOJICA ARANQUE, Carlos Alberto Et.al. Justicia restaurativa. Hacia una nueva visión de la justicia penal. Ed. Universidad de Medellín. Medellín. 2005.

PRANIS, K. Manual para facilitadores de círculos de diálogo en instituciones educativas. Fundación pedagógica nuestramérica. Costa Rica, 2009.

RAMOS MORALES, María Leonor. Los elementos del perdón en la mediación familiar. Tesis Doctoral. Consultar repositorio del DMASC. www. Facdyc.uanl.mx. México, 2017.

REY NAVAS, Fabio Iván. La justicia restaurativa como un fin de la pena. ED. Ibáñez. Bogotá, 2018.

SÁNCHEZ GARCÍA, Arnulfo. Mediación y arbitraje. Eficacia y proyección internacional. México, D.F,: Tirant Lo Blanch. 2015.

TAMARIT SUMALLA, Josep. Et.al. La Justicia restaurativa desarrollo y aplicaciones. Ed. Comares. Granada, 2012.

WACHTEL, Ted. Et.al. Reuniones de justicia restaurativa. Real Justice y Manual de reuniones restaurativas. Ed. International Institute for Restorative Practices. Pennsylvania, USA. 2010.

ZEHR, Howard. El pequeño libro de la justicia restaurativa. Ed. Good Books. España. 2007.

Submetido em: 22/03/2019

Aceito em: 27/04/2019 